WellBeing International

WBI Studies Repository

Spring 2011

\title{
Cognitive Relatives Yet Moral Strangers?
}

Judith Benz-Scharzberg

International Centre for Ethics in the Sciences and Humanities

Andrew Knight

Oxford Centre for Animal Ethics

Follow this and additional works at: https://www.wellbeingintlstudiesrepository.org/acwp_awap

Part of the Animal Studies Commons, Ethics and Political Philosophy Commons, and the Other Anthropology Commons

\section{Recommended Citation}

Benz-Schwarzburg, J., \& Knight, A. (2011). Cognitive relatives yet moral strangers?. Journal of Animal Ethics, 1(1), 9-36.

This material is brought to you for free and open access by WellBeing International. It has been accepted for inclusion by an authorized administrator of the WBI Studies Repository. For more information, please contact wbisr-info@wellbeingintl.org.

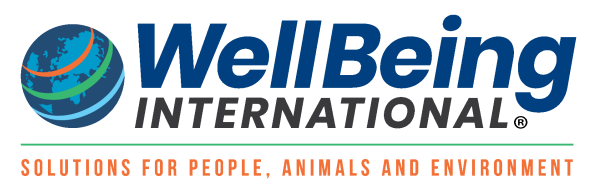




\title{
Cognitive Relatives yet Moral Strangers?
}

\author{
Judith Benz-Schwarzburg ${ }^{1}$ and Andrew Knight ${ }^{2}$ \\ ${ }^{1}$ International Centre for Ethics in the Sciences and Humanities (IZEW) \\ ${ }^{2}$ Oxford Centre for Animal Ethics
}

\section{KEYWORDS}

cognition, culture, language, theory of mind, great apes, dolphins, animal welfare, enrichment, personhood, inalienable rights, human rights

\section{ABSTRACT}

This article provides an empirically based, interdisciplinary approach to the following two questions: Do animals possess behavioral and cognitive characteristics such as culture, language, and a theory of mind? And if so, what are the implications, when long-standing criteria used to justify differences in moral consideration between humans and animals are no longer considered indisputable? One basic implication is that the psychological needs of captive animals should be adequately catered for. However, for species such as great apes and dolphins with whom we share major characteristics of personhood, welfare considerations alone may not suffice, and consideration of basic rights may be morally warranted-as for humans. Although characteristics supporting the status of personhood are present to differing degrees among the diverse array of animal species, this is a barrier to moral consideration only if anthropocentric, exclusive, and monolithic viewpoints about the necessary prerequisites for personhood are applied. We examine the flaws inherent within such positions and argue for inalienable species-appropriate rights.

\section{Introduction}

The comparison of the cognitive abilities ${ }^{1}$ of adults with those of children and of humans with those of nonhuman animals (hereafter "animals") have long been topics of significant philosophical interest. ${ }^{2}$ Considered sources of "pure natural behavior," children and animals have provided valuable insights into human nature, which have supported the proposition that the human adult is what the child is not yet able to be and what the animal will never be (Gigon, 2002, pp. 63-64).

Clearly, humans are endowed with exceptional social, cognitive, and other psychological capacities. We form cultures, use languages, and interact with one another, cooperatively, competitively, and in other ways. The purported human-uniqueness of such abilities has long been considered adequate justification for attributing to humans a moral status markedly superior to that granted to animals and for justifying very different standards of treatment.

However, empirical studies from different scientific fields provide increasing evidence that certain animals demonstrate at least some aspects of these phenomena. Accordingly, a review of the moral status and treatment of such animals is warranted. In this article we review such evidence, focusing on animals' cultural, linguistic, and psychological capacities. We examine the implications in two important cases: the 
welfare of captive animals and the case for granting basic rights to animals, similar in some respects to fundamental human rights.

\section{Animal Cultures}

Van Schaik and colleagues (2003) provided a broad definition of culture as "a system of socially transmitted behavior" (p. 102). Whiten (2005) further specified that the culture of a community consists of a unique array of traditions (p. 52). These traditions must demonstrate a certain level of complexity, they must be transmitted to new individuals through specific learning mechanisms, and any spread to new communities must not be attributable to ecologic or genetic causes. ${ }^{3}$

\section{Culture in Chimpanzees}

Some chimpanzee traditions appear to meet these conditions. At least 39 traditional behavior patterns have been identified among seven African chimpanzee study sites (Whiten et al., 1999). Results are assembled within the Behaviour Definition and Distribution Database, ${ }^{4}$ which collates available information about these traditions, including the use of "leaf-sponges" to collect water and the so-called hand-clasp, a special handholding position during grooming, which was the first documented social tradition in chimpanzees (McGrew \& Tutin, 1978). The best-known chimpanzee cultural traditions are probably nut-cracking (Boesch \& Boesch, 1983) and termite-fishing (Goodall, 1964).

Chimpanzee traditions are very complex. Chimpanzees use different tool sets for different tasks, including different two-part sets when confronted with different types of insects and their mounds or nests (Sanz, Call, \& Morgan, 2009; Sanz, Morgan, \& Gulick, 2004; Sanz, Schöning, \& Morgan, 2009). They manipulate and modify potential tools, for example, by removing parts, shortening them to appropriate lengths, or abrading the materials. They use tools for very different purposes, and their traditions show both technological and sociological aspects.

An interesting example recently reported by Hernandez-Aguilar, Moore, and Pickering (2007) was the use of tools by savanna chimpanzees in Ugalla, Tanzania, for harvesting the underground storage organs of plants such as root vegetables. This behavior is considered to have played a key role in the initial hominin colonization of savanna habitats, in the development of the skull and tooth morphology of the genus Australopithecus, and in the evolution of the genus Homo-the underground storage organs of plants served as "fallback foods" in times when food was scarce (Hernandez-Aguilar et al., 2007, p. 19210).

The underlying learning mechanism of culture transmission in chimpanzees has been described as utilizing a "master-apprenticeship" relationship (Matsuzawa et al., 2001). Although direct assistance or active teaching by the skilled master is absent, such masters nevertheless interact socially with their naive apprentices. They show unusually high levels of tolerance and allow long-term repetitive observation, with access to tools. ${ }^{5}$ Captive chimpanzee mothers have been observed to offer tools to their infants (Hirata, 2006, pp. 202, 209-211). In addition, infants selectively use the same tools chosen by adults, which indicates that tool selectivity is transmitted (p. 211). Other experimental data on captive chimpanzees similarly shows evidence of the transmission of traditions (Whiten, Horner, \& de Waal, 2005).

As with human infants, learning by young free-living chimpanzees occurs at certain sensitive ages, within very strong mother-infant interactions (Lonsdorf, 2006). However, human children appear more strongly reliant on imitation, choosing to imitate actions demonstrated, even when it becomes obvious that such actions will no longer achieve desired goals. In contrast, apes change from imitative to emulative behaviors—-that is, flexible behaviors more likely to achieve such goals (Horner \& Whiten, 2005). ${ }^{6}$ 


\section{Culture in Other Great Apes}

Cultural traditions have also been described in other great apes. Van Schaik and colleagues reported at least 19 highly complex behavioral patterns in orangutans in Borneo, serving a wide range of purposes relating to the achievement of subsistence, comfort, or social communication (van Schaik et al., 2003; van Schaik, van Noordwijk, \& Wich, 2006). Tool use in free-living gorillas in northern Congo has been similarly described. Examples include the use of sticks, branches, and trunks for different purposes, including as walking sticks and as poles to determine water depth (Breuer, Ndoundou-Hockemba, \& Fishlock, 2005).

\section{Culture in Other Animals}

Tool use is certainly not limited to great apes. Australian bottlenose dolphins, for example, use marine sponges as foraging tools. Genetic analysis has indicated that transmission of this behavior occurs matrilinearly ${ }^{7}$ (Krützen, 2005).

New Caledonian crows are also skilled tool users, as was exemplified in a 2002 report from British scientists (Weir, Chappell, \& Kacelnik, 2002). A young female was observed using a wire to extract a small bucket containing food from a tube. When at first she was unsuccessful using a straight piece of wire, she bent the wire into a hook, with which she successfully extracted the bucket-despite no prior experience with the material or situation. Hunt and Gray similarly reported that New Caledonian crows modify pandanus tools, ${ }^{8}$ from straight ones to a variety of stepped tools, ranging from single- to multistep tools with greater efficiency (Hunt \& Gray, 2003, pp. 867, 872-873). This could indicate diversification and evolution of tool designs, although to date supporting examples have been described only in New Caledonian crows and chimpanzees (Whiten, 2005, p. 53).

In some respects, tool use in New Caledonian crows seems to represent innate behavior. However, social input nevertheless plays an important role in the transmission and evolution of specific techniques and tool designs. Young crows in captivity, for example, prefer to use objects that they have observed a human using (Kenward, Rutz, Weir, \& Kacelnik, 2006, p. 1340; Kenward, Weir, Rutz, \& Kacelnik, 2005).

Recently, even meta-tool use ${ }^{9}$ has been observed in New Caledonian crows. Taylor, Hunt, Holzhaider, and Gray (2007) observed crows mastering recursive tasks, including the use of a short stick to extract a longer stick, which was used in turn to extract food from a box.

\section{Culture in Animals and Humans}

Certain animal behaviors appear to meet reasonable definitions of culture, at least in the case of the highly complex and socially transmitted traditions among chimpanzees and orangutans. Tool use in cetaceans and corvidae, for example, also seems to possess cultural aspects.

Obviously, many (although not all) human cultural activities demonstrate great depth and complexity, as evidenced by achievements such as elaborate artistic performances or creations and advanced technological constructions. Yet such complexity is not necessary for the manifestation of culture (Sommer, 2007). If it were, the cultures of many contemporary human and early hominin communities could not be acknowledged as such.

In fact, human cultures are socially acquired, usually between birth and adulthood. Children pass through all stages, from non-cultural newborns to encultured children and teenagers, during which time they become progressively more aware of the traditions of their societies (e.g., Rogoff, 2003). On the other hand, culture also represents behavioral patterns that have evolved over many generations. For example, early hominin culture included ivory sculptures produced during the middle and late Pleistocene, more 
than 30,000 years ago (e.g., Conard, 2007), and Oldowan stone tools, ${ }^{10}$ which are about 2.5 million years old (e.g., Semaw, 2000). Such cultural achievements have since evolved into those of modern art and technology. Acknowledging the evolutionary and developmental progression of human culture overcomes the common misperception that our culture is necessarily divorced from the natural world. ${ }^{11}$

\section{Animal Language}

The characteristic most prominently used to argue for a moral distinction between humans and animals has been our purportedly unique ability to speak. ${ }^{12}$ However, considerable research has investigated the communicative abilities of animals.

\section{Language in Chimpanzees}

In 2007, one of the most famous contributors to chimpanzee linguistic studies passed away. By the time of her death, Washoe the chimpanzee had successfully mastered around 250 distinctive American Sign Language (ASL) signs, some of which she had taught to her adopted son Loulis and two other chimpanzees. This was claimed to be the first animal-to-animal transfer of a human language. These chimpanzees routinely used-and continue to use-ASL, vocalizations, and gestures in their interactions with humans and each other.

Widespread initial excitement about Washoe's reported language abilities (Gardner \& Gardner, 1975) was followed by several criticisms, including claims that Washoe's apparent linguistic skills actually may have been more reflective of the techniques used to teach her than of her innate abilities (Seidenberg \& Petitto, 1979). For some, however, Washoe's various reputed abilities stimulated a fundamental reexamination of chimpanzee psychology (Fouts, 2000).

Other apes also have communicated with humans using sign languages or symbols (via boards or computers). Such apes have demonstrated their ability to use language creatively by inventing new combinations of words (e.g., combining labels for "white" and "tiger" to describe a zebra and combining labels for "listening" and "drinking" when confronted with a fizzy tablet in water), and they have generalized to new contexts words learned within a specific context. ${ }^{13}$

\section{Language in Monkeys}

Animals' communicative abilities are also demonstrated by their natural means of communication. Perhaps the most complex examples of "proto-syntax" in animal communication discovered to date have been described recently in Campbell's monkeys (Ouattara, Lemasson, \& Zuberbühler, 2009). These monkeys vocalize six different types of alert calls, which are combined within long sequences in highly context-specific ways. Stereotyped sequences convey information about group cohesion and travel, falling trees, neighboring groups, non-predatory animals, nonspecific predatory threat, and specific predator classes. Callers follow relatively sophisticated principles when concatenating sequences, including nonrandom transitions between call types, incorporation of specific calls within existing sequences to form new ones, and recombination of two sequences to form a third. Ouattara and colleagues concluded that these primates have overcome some of the constraints of limited vocal control through combinatorial organization.

Seyfarth and Cheney (1993) similarly described the use of different alarm calls for different predators in vervet monkeys. It has been postulated that these alarm calls also fulfill the function of words with semantic content. 


\section{Language in Dolphins}

One of the most interesting acoustic and non-acoustic communication systems with language-like features is dolphins' use of whistles, echolocation clicks, and certain postures and behaviors. Although related research remains in its infancy, it is already known, for example, that dolphins use signature whistles for each individual, equivalent to names, which aptly demonstrates their awareness of the individuality of other dolphins and themselves (Janik, Sayigh, \& Wells, 2006; White, 2007, pp. 56-57, 96116, 141-146). Dolphins are also able to understand instructions given to them in artificial languages, consisting of acoustic, computer-generated whistles or hand gestures. They seem to understand these arbitrary symbols and the rules used to combine them because they follow instructions perfectly when a sentence is semantically reversed. For example, to both humans and dolphins, the English sentence "Go to the hoop at the surface and take it to the basket at the bottom" means something quite different when "hoop" and "basket" are exchanged (White, 2007, pp. 96-116, especially p. 100, with reference to Hermann, Richards, \& Wolz, 1984).

\section{Language in Parrots}

Language comprehension studies in parrots are especially interesting because of their ability to pronounce many human words. Irene Pepperberg worked with her African Grey parrot Alex for more than two decades, until his death in 2007 (Pepperberg, 2002, 2008). ${ }^{14}$ She described her use of the so-called Modal-Rival Training System to introduce new words, which appears particularly effective: One person acted as a trainer, and a second person acted as a model for Alex, as well as being a rival for the attention of the trainer. When the model and rival engaged in a conversation about a new item, Alex intruded, naming the item, apparently motivated by curiosity, jealousy, and a desire to regain the attention of the trainer.

A flexible learning situation was created. The roles of the questioner and the respondent were reversed among the humans, occasionally including the bird in interactions. Alex did not simply hear stepwise vocal duets, "but rather observed a communicative process that involves reciprocity." He learned that communicating with the labels was an interplay-"a two way street in that one person is not always the questioner and the other always the respondent"-and a process that "can be used to effect environment change" (Pepperberg, 2002, pp. 26-29, esp. 26). He acquired, for example, names of different objects, colors, materials, and numbers. Even short sentences (e.g., "wanna go" requests), as well as interrogative pronouns, were part of his vocabulary. Additionally, he knew the words "color," "same," and "different."

When shown different toys, Alex demonstrated several skills related to object classification (Figure 1). He was able to tell whether a toy fell within a certain category. If shown a red key and a yellow wooden cube, for example, and asked, "What toy red?" he would answer, "Key!" But Alex could also classify objects with respect to different categories. When shown the yellow wooden cube and asked, "What color?" he would answer, "Yellow." If asked, "What matter?" his answer was "wood." Especially impressive was his ability to classify objects as similar or different with respect to different categories. When confronted with a yellow wooden cube and a yellow key and asked, "What's same?" his answer was "color"-even if he had never seen this color before. When asked, "What's different?" he answered, "Matter" (Bartels, 2005, pp. 156186, especially 175-181; Pepperberg, 2002).

In over $80 \%$ of cases, Alex answered correctly when asked three different questions about the same visible item. ${ }^{15}$ If he did not understand, he would have been expected to provide the same response in all three cases or to give responses determined by chance. Alex thereby demonstrated the ability to modify 
his response according to auditory stimuli from different questions, while the visual stimuli remained constant (hence demonstrating independence from these visual stimuli).

The existence of concepts is closely linked to the existence of "meta-concepts." For example, a speaker who is aware that she or he has made a mistake must be able to have a thought now considered to be correct, about a former belief now considered to be false (Tietz \& Wild, 2006, p. 18). In a strict sense Alex could not correct his reaction after receiving additional information, but he was able to modify it (Bartels, 2005 , p. 178). Furthermore, his concepts were clearly organized in small networks, including main categories such as color and subcategories such as yellow, red, and green (Pepperberg, 2002, p. 184). According to Andreas Bartels, who refers to Donald Davidson, ${ }^{16}$ these last two characteristics meet the two most important criteria for the possession of concepts (Bartels, 2005, p. 178). Alex clearly had an understanding of perception-based concepts, which, though different from human concepts, can nevertheless be functionally interpreted and described (Bartels, 2005, pp. 11, 185-187; see similar in Newen \& Bartels, 2007). Alex's concept for yellow, for example, had three functional roles: to indicate, classify, and compare (see Figure 1 and Bartels, 2005, p. 184).

Figure 1: Alex, an African Grey parrot, demonstrated several skills related to object classification. According to Bartels (2005), the parrot's concepts can be described via functional roles.

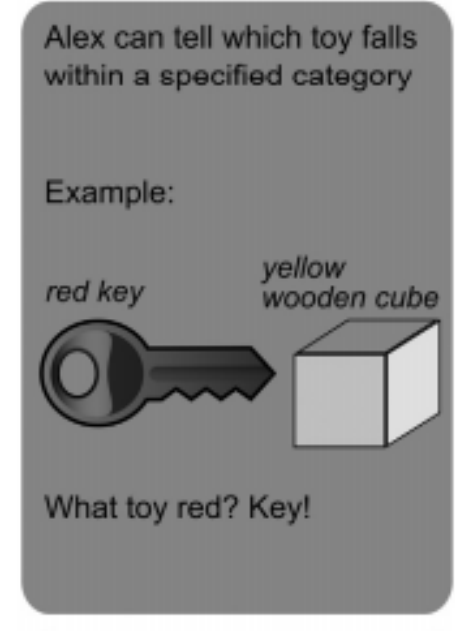

Indication function

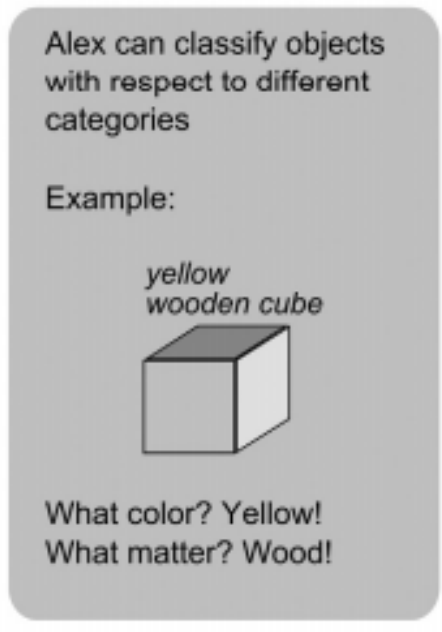

Classification function

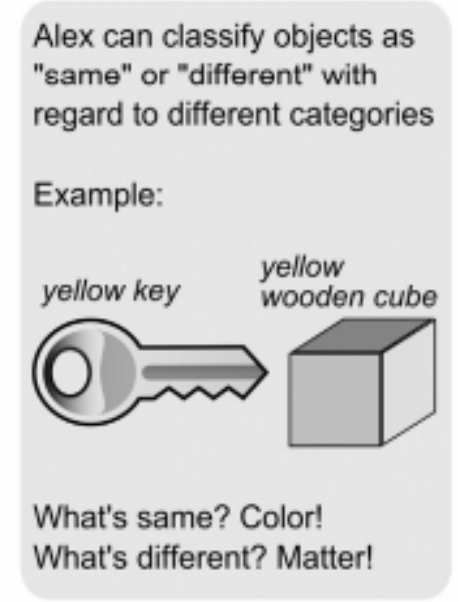

Comparison function

Based on this philosophical interpretation of concepts, Alex possessed perceptionbased concepts, or conceptual representations, which are organized within small networks and can be described functionally. Although these are not nearly as complex as the concepts underlying human language, they can nevertheless be regarded as another important example of preliminary linguistic ability in an animal. ${ }^{17}$ Without concepts there can be no language or linguistic capacity.

\section{Animal Theory of Mind}

Theory of mind is also a consciousness-based core capacity of human beings, and there is some evidence of it in animals. The term theory of mind (ToM) describes a commonsense psychology (Bartsch \& Wellmann, 1995, p. 4). Those who have a ToM impute mental or psychological states to themselves and others. Such states include beliefs and desires, as well as perceptual states such as seeing (BischofKöhler, 2000, p. 9; Premack \& Woodruff, 1978, p. 515) ${ }^{18}$ The assumption that everybody holds such 
mental states serves to explain and predict social behavior and interaction (Bartsch \& Wellmann, 1995, p. 5).

\section{Theory of Mind in Chimpanzees}

In crucial experiments investigating chimpanzee knowledge of perceptual states, groups of two individuals competed for hidden food items (Hare, Call, Agnetta, \& Tomasello, 2000; Hare, Call, \& Tomasello, 2001). In one of the tests, the subordinate chimpanzees could see the hiding process and could also see whether the dominant chimpanzees had seen the hiding process, based on their doors being opened or closed. The subordinates then avoided food that the dominants had observed being hidden but retrieved food that they had not (Hare et al., 2001; Tomasello, Call, \& Hare, 2003a, p. 154). ${ }^{19}$ This indicated that the subordinate chimpanzees knew the dominant chimpanzees had seen something at an earlier time, knew that the dominant chimpanzees were likely to remain aware of this at a later time, and knew that this awareness was likely to determine the dominant chimpanzees' behavior.

The significance of these results remains under discussion. Whether they clearly indicate that chimpanzees have a ToM is controversial (Povinelli \& Vonk, 2003), but they do add to a weight of accumulating evidence (Call \& Tomasello, 2008; Tomasello et al., 2003a, p. 156; Tomasello, Call, \& Hare, 2003b). Combined evidence from multiple studies suggests that chimpanzees understand the intentions, goals, visual (and sometimes auditory) perception, and knowledge of other chimpanzees. Even if there is no evidence (yet) of understanding false beliefs, ${ }^{20}$ they seem to understand others within a perception-goal psychology (Call \& Tomasello, 2008; Kaminski, Call, \& Tomasello, 2008; Krachun, Carpenter, Call, \& Tomasello, 2009).

Tomasello and colleagues (2003a) concluded that "chimpanzees-and perhaps other animal speciespossess a social-cognitive schema" (p. 156) that helps them understand something about the intentional structure of behavior and about how perception influences it. This social-cognitive schema is clearly not a "full-blown" or "human-like" ToM. On the other hand, Tomasello and colleagues concluded that it was "simply too sweeping" to understand ToM as something monolithic ${ }^{21}$ that exclusively incorporates human cognitive characteristics, while completely excluding those of other species. They suggested that further research should focus on determining which of the many different kinds of psychological states chimpanzees are able to comprehend and on describing the extent to which they are able (p. 156).

\section{The Incremental Progression of Cognitive, Social, and Psychological Capacities}

As with culture and language, ToM consists of many different sociocognitive processes and abilities, constituting a "toolkit" with different components or building blocks. False belief understanding may be a core capacity, but there are other core capacities such as understanding perceptual states that are included within the classical definition of ToM provided by Premack and Woodruff in 1978.

Reducing, for example, ToM to false-belief comprehension, culture to advanced technical specialization, or language to grammar competence ignores the bundled character of cognitive, social, and psychological abilities. Claiming that an individual possesses culture, language, or ToM only when showing the full spectrum of subsumed capacities denies the incremental evolutionary and ontogenetic development of these abilities within and between species. ${ }^{22}$ Animals and humans who lack the full spectrum of capacities yet, or who no longer possess them, are by definition excluded. Asserting that the full spectrum must be congruent with the abilities of a healthy human adult is even more exclusive than anthropocentrism-which discriminates in favor of all humans generally, rather than privileged subsets. The failure of such claims is linked to their premises and unsatisfying definitions of cognitive, social, and psychological abilities, rather than the application of cognition theory to animals. 
The limitations of monolithic and exclusive conceptualizations of ToM, for example, are exemplified by examining ToM in children. The classical ToM test for children is called the Maxi Test, ${ }^{23}$ which reveals children's level of understanding of false beliefs. The test utilizes the following story: Maxi stores his chocolate in the green kitchen cupboard, but while he is playing in the garden, his mother removes it to the blue one. Children are then asked where Maxi will search for the chocolate when he returns to the kitchen. Three-year-olds mostly answer, "In the blue cupboard," whereas almost $50 \%$ of 4 -year-olds and more than $80 \%$ of 5 -year-olds answer, "In the green cupboard." Thus, based on this classical test designed by Wimmer and Perner (1983), most 3-yearolds are unable to distinguish between their own knowledge and that of Maxi. Even when alerted to the fact that Maxi did not witness his mother moving the chocolate, they still expect him to search the blue cupboard. They have not yet perceived that knowledge states depend on information received and that different people may therefore possess different knowledge states and subsequently might harbor false beliefs if their knowledge is incomplete or incorrect (for a brief discussion of the Maxi Test, see Kasten, 2005, pp. 134-137).

Results from false-belief tests indicate that children younger than 4 to 5 do not understand false beliefs (Bischof-Köhler, 2000, p. 11; Kasten, 2005, p. 135). But does this mean that children younger than 4 years old do not possess a ToM? Is it instead possible that available tests may simply fail to show the ToM abilities of children between 2 and 4 years of age?

There are obviously problems connected with false-belief tests such as the Maxi Test. Such tests presuppose significant additional cognitive abilities (such as linguistic abilities, given that the tests are normally language-based). They result only in a pass or fail and cannot provide quantitative measures of ability. This correlates with monolithic conceptualizations of ToM as a characteristic entirely present or entirely absent, which fails to detect or acknowledge its progressive development. As Workman and Reader (2004) put it, "since the test ${ }^{24}$ is all-or-none . . . it has the effect of making what might be a gradual developmental profile look like a sudden stage-like shift" (p. 128). Finally, although such tests examine the relatively sophisticated understanding of false beliefs, and although such understanding may constitute a cornerstone of ToM, it is far from being the only important characteristic. The limitations of false-belief tests are increasingly acknowledged, with researchers expressing their disaffection with existing paradigms in general and specifically. Gopnik and colleagues aptly expressed such sentiments: "There is an unfortunate syndrome loose in developmental psychology: call it "neurotic task fixation"' (Gopnik, Slaughter, \& Meltzoff, 1994, cited by Hülsken, 2001, p. 7).

At least two lines of argument support approaching the ToM of children via other methods and applying new theoretical frameworks. First, results from non-languagebased false-belief tests indicate that 15month-old infants already "possess (at least in a rudimentary and implicit form) a representational ToM: they realize that others act on the basis of their beliefs and that these beliefs are representations that may or may not mirror reality" (Onishi \& Baillargeon, 2005, p. 257). Similarly, Buttlemann, Carpenter, and Tomasello (2009) presented positive results from an active helping paradigm, involving false-belief understanding in 18-month-old infants.

Second, children younger than 4 are known to use mental verbs (e.g., "know," "think," and "believe") and other terms of mental reference in a meaningful way, in their everyday child language. Researching the way children talk about the mind is made possible through linguistic databases such as the Child Language Data Exchange System (CHILDES), ${ }^{25}$ which contains transcribed conversations. Above all, analyses of the data demonstrate that very young children use so-called contrastives: utterances that mark different mental states within one sentence or a very small context. As defined by Bartsch and Wellmann (1995), 
Contrastive utterances, which distinguish a person's thoughts and beliefs from other states of affairs, potentially come in several overlapping varieties: Those contrasting belief with reality, fiction with belief, one's own mental state at one time with a later changed state, one's own mental state with another's, the contrasting mental states of two other people, and so on. ${ }^{26}$ (p. 44)

Such contrastive utterances might be of the form "I didn't know X, but now I know X" or "You think X, but I think Y." According to Bartsch and Wellmann (1995), contrastives emerge in child language well before the fourth birthday, at a mean age of 3 years. The children they studied were between 2 years 8 months and 3 years 8 months when such utterances were first used (and they might have used them even earlier, when no tape recorder was present; p. 47).

An analysis of the CHILDES data about two German girls named Caroline and Simone supports these findings for the German child language: contrastives were used by Caroline at the age of 2 years and 1 month and by Simone at the age of 2 years and 7 months (Benz, 2004, pp. 50-59, 75-89, 106-108). Caroline was 2 years and 5 months old when she participated in the following conversation with her mother:

Table 1: Contrastive Use by Caroline (Age 2 years 5 months) in Conversation With Her Mother

\begin{tabular}{|c|c|c|c|}
\hline \multicolumn{2}{|r|}{ German Dialogue } & \multicolumn{2}{|c|}{ Translation by J. Benz-Schwarzburg } \\
\hline Mother: & $\begin{array}{l}\text { Die Aysche sagt das finde ich aber } \\
\text { kein gutes Spiel. }\end{array}$ & Mother: & Aysche says that's not a nice game. \\
\hline Child: & $\begin{array}{l}\text { Ich aber find lustig wenn Aysche runter } \\
\text { hoppala. }\end{array}$ & Child: & $\begin{array}{l}\text { But I think it's funny, when Aysche } \\
\text { falls down. }\end{array}$ \\
\hline Mother: & $\begin{array}{l}\text { Findest du lustig wenn die Aysche } \\
\text { runterfällt? }\end{array}$ & Mother: & $\begin{array}{l}\text { You think it's funny, when she falls to } \\
\text { the ground? }\end{array}$ \\
\hline Child: & Ja und au. & Child: & Yes and ouch. \\
\hline
\end{tabular}

Caroline very clearly points out that she, in contrast to her mother, likes the idea of Aysche falling to the ground. She even confirms her statement and indicates what she considers to be so funny: the fact that Aysche hurts herself (Benz, 2004, p. 82).

The importance of this conversation becomes apparent when considering that most developmental psychologists recently believed, or indeed still believe, that children younger than $31 / 2$ to 4 lack a ToM. Bischof-Köhler (2000) states,

Children under the age of three and a half years are naïve realists. . . . That is, they don't understand yet that their beliefs about facts are just beliefs that may represent those circumstances appropriately as well as inappropriately. They also take it for granted as a matter of course that other persons live in the same reality and that they percept and know exactly the same things they do. They don't apprehend yet that other persons can hold different opinions on the same fact. . . . This changes when a theory of mind appears at about the age four." (p. 11, see similar p. 34, translation J. Benz-Schwarzburg)

This viewpoint is clearly rendered incorrect by Caroline's narrative and similar data. 
Research on ToM in animals as well as infants has demonstrated that this complex phenomenon cannot correctly be considered an all-or-nothing trait. This is similarly true for other higher cognitive abilities (DeGrazia, 2006, p. 42). Moreover, the human ToM does not suddenly appear but emerges gradually during ontogeny. ${ }^{27}$ Children already possess some of its components before the age of 4 , as shown by nonlinguistic tasks and contrastive utterances (Bartsch \& Wellmann, 1995, p. 47; Benz, 2004, pp. 106108; Buttlemann et al., 2009; Onishi \& Baillargeon, 2005). It therefore seems appropriate to reject monolithic concepts of ToM, at least when considering the evolution and ontogeny of social cognition (Tomasello et al., 2003b, p. 240).

Disregarding these arguments leads to an unsatisfying simplification of the phenomenon of ToM and inhibits comparative research between species or between different age or ability groups (such as healthy vs. otherwise) within species. However, accepting the conceptual and methodological challenges of defining and testing cognitive abilities yields important implications for future research: we need nonlinguistic false-belief tests for children and animals (Onishi \& Baillargeon, 2005, p. 257) and speciesappropriate tests in general. We should abandon all-or-nothing test designs that correlate with monolithic conceptualizations of cognitive abilities and should instead focus on their incrementally progressive character.

\section{Ethical Implications of Animal Abilities}

The moral consideration afforded to animals is markedly less than that afforded to most humans (exceptions may include, for example, victims of major human rights violations). The main justifications for such profound differences in moral consideration and treatment depend on major purported differences in cognitive and related psycho-sociological capacities, such as culture, language, and ToM. ${ }^{28}$ However, studies increasingly suggest the existence of such characteristics - or at least of important aspects of these and other cognitive abilities-in some animal species. Additionally, as pointed out by Rogers and Kaplan (2004), we must consider that "only a handful of species have been researched and current findings would suggest that many more species might be found to have exceptional cognitive abilities, if we only looked" (p. 193).

To what extent has such changing awareness altered the human-animal relationship? Unfortunately, to date the answer remains "very little." Although the cognitive relationship of some animals to humans is far closer than previously believed, on the whole we continue to treat such cognitive relatives as moral strangers, denying them moral consideration to an extent very rarely applied to our fellow human beings.

Acknowledging this changing awareness of animal abilities yields a range of implications, from the basic to the profound. One basic implication is that the psychological needs of captive animals should be adequately met. However, this presupposes that keeping animals in captivity is ethically defensible, as long as welfare standards are upheld.

A more profound implication is that welfare considerations alone may not suffice and that consideration of basic rights may be morally warranted for species such as great apes and dolphins with whom we share major characteristics of personhood. The granting of such rights might, for example, disallow the involuntary confinement of such animals in captivity. Each of these implications is examined in the following sections.

\section{Environmental Enrichment for Captive Animals}

Although it has long been understood that involuntary confinement may fail to meet the physiological needs of captive animals, it is increasingly understood that the advanced cognitive, other psychological, and social characteristics of some species may make it very difficult to cater adequately to their 
psychological needs in captivity. The great apes-our closest nonhuman relations-provide obvious examples. ${ }^{29}$ As Rogers and Kaplan (2004) have asserted, "the ultimate aim must surely be that we do not just want animals to survive but want them to have a quality of life commensurate with their needs and dignity: physical, psychological, social, and cultural" (p. 196).

Zoos are increasingly aware of such psychological, social, and cultural needs of captive animals, and increasing numbers of modern zoos have accordingly attempted to enrich their lives by providing them with additional stimuli (see Jantschke, 1997, p. 406). Common examples include the introduction of novel items to enclosures, or the provision of visual and olfactory cues. Such interventions are directed at stimulating curiosity-driven or investigative behavior, which results in mental and physical activity or exercise and decreases stereotypical and undesirable behavior indicative of chronic stress (see Hutchins, Kleiman, Geist, \& McDade, 2003, pp. 203-204). Since 2009, Great apes at the Leipzig Zoo in Germany, for example, have been provided with so-called shaking-boxes, rotary discs, and food-knots. ${ }^{30}$ Unfortunately, however, environmental enrichment efforts remain poor or absent in many institutions internationally. And the ethical case for enrichment has scarcely been addressed by philosophers to date. $^{31}$

An exception is David DeGrazia (1996, pp. 258-297, especially pp. 294-297). His arguments are grounded in the basic principle of non-maleficence, which exhorts us "not to cause extensive unnecessary harm to others without their consent." This principle is further elaborated within 15 rules, 2 of which directly address the keeping of animals in zoos: Rule 3 is "don't cause significant suffering for the sake of your or others' enjoyment," and rule 14 is "provide for the basic physical and psychological needs of the zoo animal, and ensure that she has a comparably good life to what she would likely have if in the wild" (pp. 258-281). ${ }^{32}$ This last rule clearly asserts psychological needs and the necessity of providing comparable life conditions. DeGrazia's ethical evaluation of zoos according to these principles provides the conclusion that in most cases they can adequately provide for their animals' needs, even if too few presently do (pp. 290, 296).

However, adequately catering for certain animals is rendered particularly difficult by their advanced cognitive, psychological, and social characteristics. According to DeGrazia (1996), keeping great apes in zoos is ethically defensible only if zoos can guarantee family preservation, considerable space, and highly enriched environments, containing ample opportunities for climbing, exploring, problem-solving, and playing (p. 297). ${ }^{33}$ In such cases psychological needs arising from cognitive abilities are central to assessments of welfare, demonstrating the necessity of species-specific welfare assessments and species-appropriate environmental enrichment. Again, underlying all such considerations, however, is the assumption that keeping animals in captivity is ethically defensible, as long as welfare standards are upheld.

Rights and Responsibilities Implied by Cognitive, Psychological, and Social Abilities

Do we, however, owe animals more than best-practice welfare standards? After all, animals such as great apes possess to varying degrees cognitive, psychological, communicative, and social attributes once considered uniquely human, characteristics that have previously served to support the establishment of human rights. The following question therefore arises: Is it ethically justifiable at all to subject such animals to involuntary confinement within zoos or elsewhere?

Interestingly, DeGrazia (1996) rejects keeping dolphins in zoos because of the practical impossibility of providing them with surroundings in aquatic exhibits sufficiently comparable to those of their natural habitats (p. 297). In doing so he establishes a moral line, beyond which even compliance with the best 
welfare standards cannot be considered adequate to justify the involuntary confinement of certain species.

Thomas White (2007) describes his view of this moral line by noting that our expectations of certain treatment standards from other people stem from our self-identification as "self-conscious, unique individuals who are vulnerable to a wide range of physical and emotional pain and harm, and who have the power to reflect upon and choose our actions." Because we value these traits so deeply, we rarely consider it acceptable for other people to hurt, coerce, threaten, or manipulate us.

We object to such actions so strongly that we label them not just "inconvenient" or "unpleasant," but as "wrong." Ethics—our labeling actions as "right" or "wrong"-is grounded in the idea that the type of consciousness that we have gives us special capacities and vulnerabilities. When we label something as "wrong," then, we're saying that it crosses the line with regard to not respecting some fundamental feature that makes us human. (White, 2007, p. 155)

Immanuel Kant described certain human core characteristics as providing sufficient justification for the granting of inalienable human rights. He asserted that the human being is an end in itself (German: Selbstzweck) and has dignity (German: Würde). Kant (1785/2008) deduced that there are conditions and expressions of (well-)being and personhood that a person should never be deprived of ( $p$. 65; see also Hilpert, 1998, p. 675 , and footnote 41$)^{34}$

Similarly, the advanced cognitive, psychological, and social abilities of animals such as dolphins and great apes confer special capacities and vulnerabilities on them, including a profound ability to suffer when deprived of fundamental psychological or social requirements. Increasing numbers of ethicists and biologists argue that these animals share with us fundamental characteristics of personhood, such as consciousness and self-consciousness, a wide range of cognitive abilities (including those giving rise to culture, language, ToM, and other abilities such as episodic memory), and the capacity to experience a wide range of emotional states (including, for example, happiness, fear, and empathy). ${ }^{35}$ It is therefore arguably more accurate to consider such animals as nonhuman persons, ${ }^{36}$ who should be granted at least basic rights concordant with those granted to humans. One implication is that the moral boundary that ethical actors are obliged to respect is violated when these animals are subjected to a range of contemporary human purposes, such as confinement within zoos and involuntary participation within biomedical research. ${ }^{37}$

The Great Ape Project, founded by Peter Singer and Paola Cavalieri, similarly argues for an extension of the "community of equals" to include all great apes. It calls for equivalence of basic rights among all members, including the right to life, the protection of individual liberty, and the prohibition of torture. The project was primarily founded in recognition of the moral significance of the cognitive abilities of great apes. ${ }^{38}$ It relies on the proximity of specifically their cognitive characteristics to those of humans, rather than phylogenetic characteristics generally-thereby implying that the community of moral consideration is potentially open to species beyond those evolutionarily close to humans, such as elephants, cetaceans, or corvidae (Cavalieri \& Singer, 1994, pp. 8-9, 463-476; similarly White, 2007, p. 11).

Despite morally important similarities, such species obviously differ from human persons (as they do from each other). Nevertheless, they could be included within such a community of moral consideration. After all, so-called marginal human persons, such as the very young, old, injured, or ill, who lack the full range of psychological and social characteristics and abilities exhibited by healthy human adults, are nevertheless valued as persons. They are valued as partially conscious, partially self-conscious, or partially autonomous beings, with unique personalities, and are accordingly granted human rights. 
It appears logically consistent to assign similar moral significance to comparable grades or stages of mental complexity in animals who possess them.

This need not necessarily imply that such nonhuman persons should be granted rights and responsibilities equivalent to those of normal human adults. The same is true of children or the mentally ill, for example. Although we may grant such people rights to life, liberty, and freedom from serious abuses such as torture, we do not necessarily stress their right or responsibility to work or their equality before the law. On the contrary, we grant them exemptions from certain social responsibilities, such as protection from child labor, and exemptions from, or mitigations of, judicial punishment. The United Nations Declaration of the Rights of the Child asserts such child-specific needs and rights. A Declaration of the Rights of Great Apes could similarly assert their specific needs and inalienable rights.

\section{Conclusions}

The Kantian foundation for human rights stems from the ideal of the rational person and the principle that every person is equally rational, self-conscious, and autonomous. ${ }^{39}$ However, the case for the equal application of human rights transcends this core idea. No matter how equal all humans actually are, all are considered equal in dignity and rights. Modern civilized societies aim to extend such moral equivalence to all human beings, no matter where they live, the color of their skin, their gender, their culture, or their cognitive capacities. Almost every country has now ratified the Charter of the United Nations, which recognizes the existence of human rights and calls for their respect and practical implementation. Most have also incorporated basic human rights within their national laws.

Such moral and social progress has been hard-won and reached only after millennia of social injustice. We should value and defend the gains we have made and seek further progress where warranted. In many countries grave human rights violations continue on a daily basis, demonstrating the need for further progress. Additionally, as ethical actors we may consciously choose whether to grant moral consideration and personhood status to beings who do not yet possess, who have possessed and lost, or who may never possess the full suite of relevant psychological and social attributes displayed by healthy human adults.

Existing evidence supports the inclusion within the moral community of persons of those animals who share with us major characteristics of personhood. What about animals whose personalities or cognitive capacities are more different from our own, however? The diversity of animals' cognitive, psychological, and social capacities yields a dilemma: such characteristics are clearly morally relevant in justifying inalienable-and hence indivisible_rights, consistent with the granting of such rights to humans; yet those same characteristics are distributed throughout the animal kingdom, where the differences of degree are frequently small. By assigning such inalienable and indivisible rights to some species but denying them completely to others, we would impose a profound all-or-nothing division on a large and diverse array of living creatures, who may differ only incrementally in the extent to which they exhibit the necessary characteristics.

Thus, frameworks such as the Great Ape Project should be considered only the beginning of a more fundamental process of reconsideration: If basic human rights such as the rights to life, liberty, and freedom from torture are relevant when morally significant cognitive, psychological, and social abilities are present in other species, then it follows logically that this should lead to corresponding inalienable rights. However, not all rights will hold the same importance for all species. Interspecies variation of morally relevant characteristics justifies the establishment of species-appropriate subgroups of rights. Some rights are more broadly applicable than others. The prohibition of torture, for example, is morally 
warranted for all species able to experience significant suffering or other adverse effects accruing from such abuse-whether or not they possess the psychological criteria for personhood.

Classical concepts of personhood rely on the possession of human-like psychological characteristics. On the one hand, the identification of such characteristics within animals, and those animals' subsequent inclusion within the community of moral consideration, facilitates their protection from a range of human abuses. On the other hand, focusing solely on human-like characteristics is intrinsically anthropocentric. We should also consider the possibility that some species might satisfy less anthropocentric definitions of personhood. White (2007) prefers to conceptualize dolphins as "alien beings" (pp. 12, 155-184) ${ }^{40}$ : Their perception of the marine world, communication, and social interactions are very different from our own. Yet these characteristics are not necessarily of lesser importance when determining moral standing. Where reasonable doubt remains about the existence of morally relevant animal characteristics, as ethical actors we should afford such animals the benefit of that doubt.

\section{Acknowledgments}

We thank Prof. Dr. Eve-Marie Engels (Chair of Ethics in the Life Sciences, University of Tübingen) and Dr. Miriam Haidle (The Role of Culture in Early Expansions of Humans research project, Heidelberg Academy of Sciences and University of Tübingen) as well as five anonymous reviewers for their helpful comments on our manuscript. We thank Prof. Dr. Hanno Würbel (University of Giessen), Prof. Dr. Albert Newen (University of Bochum), and Dr. Juliane Kaminski and Dr. Daniel Haun (both MPI EVAN, Leipzig) for their helpful discussions and the Research Training Group "Bioethics" at the International Centre for Ethics in the Sciences and Humanities, University of Tübingen, for providing a stimulating academic environment in which many of our ideas were initially developed. We thank the German Research Foundation (DFG) for partially funding this research. Any remaining flaws are solely our own responsibility.

\section{Notes}

1. The term "cognition" is used in many different ways. Fundamentally, it refers to "mental processes that are presumed to occur within the animal, but which cannot be observed directly" (McFarland, 2006, p. 32). However, this is a very broad definition-"cognitive" then becomes very similar to "psychological." To define the term more precisely, McFarland's Oxford Dictionary of Animal Behavior identifies both strict and more general meanings: "In its stricter sense, cognition refers to a particular kind of knowledge: namely 'knowing that' rather than 'knowing how.' Cognition is the manipulation of explicit knowledge. In its more general sense, cognition refers to any kind of mental abstraction of which an animal seems to be capable. ... In the study of navigation, problem solving, social interactions, deceit, language, and thinking in animals, scientists have found it necessary to postulate cognitive processes" (p. 32). To emphasize the mental abstraction underlying phenomena such as culture, language, and theory of mind, we generally intend the latter, more general definition when referring to cognition.

2. The systematic study of animal cognition first evolved during the late 1970s, when Donald Griffin (1976) established cognitive ethology as a biological subdiscipline. Increasing numbers of philosophers engaged in the topic in the 1970 s and 1980s (see Perler \& Wild, 2005). The publication of key texts by philosophers such as Peter Singer and Tom Regan helped develop the related field of animal ethics.

3. Traditions are defined as behavior patterns that are customary or habitual in at least one site, but absent elsewhere (Whiten, 2005, p. 52, Figure 1). They are shared by two or more individuals within a social unit, they persist over time, and new practitioners acquire them in part through socially aided learning (Whiten, 2005, p. 53, with reference to Fragaszy \& Perry, 2003). 
4. See the homepage of the Behaviour Definition and Distribution Database (http://culture .stand.ac.uk/chimp/) and Whiten (2005), p. 53.

5. According to Matsuzawa and his colleagues (2001), the master-apprentice relationship includes longterm repetitive exposure to a problem, which stimulates a strong motivation within the apprentice to imitate the behavior of the master. High levels of tolerance by the master are also apparent. They believe this combination to be very educationally effective. They note that some human educational traditions, such as teaching the Japanese art of sushi making, include these elements-deliberately excluding verbal explanation, written instruction, or other assistance. The sushi apprentice, for example, is traditionally forbidden to touch utensils, rice, fish, or other ingredients for years during the initial training. The apprentice just carefully observes the master, "until one day the master suddenly gives him permission to attempt making his first sushi. It is no exaggeration to say that the apprentice produces exquisite sushi from the start" (p. 573). Matsuzawa and colleagues also note that the word "educate" originates from "educe" (Latin: educere), which means "to extract." "Education" thus refers to "the drawing forth of one's potential abilities." Although active teaching is regarded to be the most advanced form of education in many societies, it may be neither the only means of educating nor necessarily the best in every circumstance. Matsuzawa and colleagues consider that such active teaching may not stimulate student motivation as effectively as the master-apprentice relationship described (pp. 572-573).

6. Horner and Whiten (2005) explored the tendency of both young chimpanzees from an African sanctuary and 3- to 4-year-old children to use emulation or imitation to solve a problem using tools, and examined whether their tendency to choose either strategy was determined by the availability of causal information. Both groups observed a human demonstrator use a tool to retrieve a reward from a puzzle box: "The demonstration involved both causally relevant and irrelevant actions, and the box was presented in each of two conditions: opaque and clear. In the opaque condition, causal information about the effect of the tool inside the box was not available, and hence it was impossible to differentiate between the relevant and irrelevant parts of the demonstration. However, in the clear condition causal information was available, and subjects could potentially determine which actions were necessary. When chimpanzees were presented with the opaque box, they reproduced both the relevant and irrelevant actions, thus imitating the overall structure of the task. When the box was presented in the clear condition they instead ignored the irrelevant actions in favor of a more efficient, emulative technique. These results suggest that emulation is the favored strategy of chimpanzees when sufficient causal information is available. However, if such information is not available, chimpanzees are prone to employ a more comprehensive copy of an observed action. In contrast to the chimpanzees, children employed imitation to solve the task in both conditions, at the expense of efficiency. We suggest that the difference in performance of chimpanzees and children may be due to a greater susceptibility of children to cultural conventions, perhaps combined with a differential focus on the results, actions and goals of the demonstrator" (p. 164).

\section{Through the maternal line.}

8. Little "spears" made of thorny leaves that are used to extract insects from holes in trunks.

9. The application of one tool to another.

10. Oldowan stone tools were first discovered at the Olduvai Gorge in Tanzania. They were used by prehistoric hominins of the Lower Paleolithic era and are the oldest manufactured tools discovered to date. 
11. The word "nature" is derived from the Latin word natura, which implies "essential qualities or innate disposition" or, more literally, "birth" (Latin: nasci). The word "culture" (Latin: cultura) stems from colere and means "to cultivate" (Hoad, 1991, pp. 108, 309). Throughout the history of philosophy and anthropology, nature and culture have been described as occupying separate spheres. Human cultures have been considered divorced from nature or from animal societies and behaviors (Grant, 1996, pp. 206-207). However, if culture is part of nature in the sense that "natural beings" (animals, as well as early hominins) also display or displayed cultural behavior, then definitions of culture as behavioral patterns present solely in modern humans, and absent in nature and other animals, become invalid.

12. Aristotle defined the human being as zoon logon echon-the being who is endowed with reason and speech (the Greek term logos refers to both). This characterization has proven very persistent throughout the history of philosophy and science. Hoffmann (2007) states that the possession of language and speech (or of central characteristics thereof) have "almost always" been claimed to be uniquely human ( $p$. 21). Very often, language is linked to thinking in general and is used as diffentia specifica to differentiate humans from other animals (Hoffmann cites examples provided by the Stoic philosophers, Descartes, Herder, Humboldt, Popper, and Eccles). Some scientists claim that language acquisition and linguistic abilities are connected to special sociocultural traits, which are more or less exclusive to human cultures and societies. Hoffman analyzes this position in regard to Herder and Humboldt but also mentions the theories of Wygotski, Wittgenstein, Tomasello, Lieberman, and others.

13. For a summary of primate language-training experiments, see Klann-Delius (1999), pp. 81-85. For reviews of animal linguistic abilities describing word invention and generalization, see Gould and Gould (1999), pp. 170-191, and Hauser (2001), pp. 215-259.

14. Pepperberg also worked successfully and still works with other African Grey parrots.

15. For Alex's ability to categorize with respect to color and shape, see Pepperberg (2002), p. 58. For his discrimination between same and different, including his transfer abilities with respect to new items, see p. 73. For his understanding of the labels, and of relative concepts, see pp. 125-167.

16. Donald Davidson (1982) writes in his essay "Rational Animals" that whether a dog can believe that an object is a tree depends on whether she or he has certain general beliefs about trees (that they need soil and water, have leaves or needles, are growing, etc.). According to Davidson, beliefs are located within a dense network of related beliefs such as this (pp. 320-321). Davidson further argues that in order to have a belief, it is necessary to have the concept of belief, which includes beliefs about beliefs (p. 324). He explains, "Much of the point of the concept of belief is that it is the concept of a state of an organism which can be true or false, correct or incorrect. To have the concept of belief is therefore to have the concept of objective truth" (p. 326). Davidson himself rejects the idea that any animal has concepts. Interestingly, Bartels (2005) and Newen and Bartels (2007) describe how some of his ideas can nevertheless be used to describe Alex's abilities.

17. It is very difficult to compare language-like or concept-like abilities in animals because very different aspects have been researched in a very diverse range of species, and interpretational frameworks that might facilitate comparison are lacking. Given that concepts or sentence-based concepts are cognitive information processes, distinctions between animals could be made by referring to different classes of informational processes (see Newen \& Bartels, 2007). Quite complex behavioral routines may result from noncognitive information processes, which do not necessarily imply concepts. These are typically stimulated by a consistent physical stimulus and trigger a consistent behavioral response (reflexes are a subcategory). No stable representation is formed that may be transferred to other contexts (Newen \& Bartels, 2007, p. 294). Cognitive information processes, however, entail nonconceptual, conceptual, and 
sentence-based or propositional representations. Nonconceptual representations are, for example, involved in the homing behavior of ants: "The spatial orientation of the ant is based on registering the position of the sun and registering the movements of its own legs. . . If you transfer the ant to a new location at the moment it finds some food, it will start to run in the direction that would have been the right one given its previous location. The representation of the location relative to its nest that is built in one context is also used in a new context. . . This indicates that the ant has built a stable representation of its spatial relation to the nest" (Newen \& Bartels, 2007, pp. 294-295). Newen and Bartels (2007) conclude that "although the homing behavior is rather flexible . . . it is nevertheless essentially dependent on key stimuli and is not based on the capacity of object identification. The lack of object representations is the main reason to claim that, in the case of the ant, the underlying representation is only a nonconceptual one" (p. 295). Real conceptual information systems (see our discussion on Alex) can identify and reidentify objects and properties and show a relative stimulus independence and a certain level of abstraction. Classification here is more than stimulus generalization; it involves class formation and the existence of minimal semantic nets (see Newen \& Bartels, 2007, p. 295). An even more sophisticated category of representations is that of sentence-based or propositional concepts. Newen and Bartels (2007) state that these concepts can so far only be ascribed to humans and the bonobo Kanzi, who is trained to formulate sentences via symbol combination. Kanzi can describe events that occurred when the listener was absent and can express desires (e.g., to walk through a forest via a specific route). They note, "Assuming . . . that the description of Kanzi's capabilities is essentially correct, Kanzi is a paradigmatic case of an animal that has propositional representations because he has conceptual representations ... and he produces compositional representations for describing events or for expressing his desires. Moreover, there is evidence that his symbolic system forms a basic natural language, partly because he can understand human natural language to a remarkable degree" (pp. 300301).

18. "In saying that an individual has a theory of mind, we mean that the individual imputes mental states to himself and to others. . . A system of inferences of this kind is properly viewed as a theory, first, because such states are not directly observable, and second, because the system can be used to make predictions, specifically about the behavior of other organisms" (Premack \& Woodruff, 1978, p. 515).

19. Moreover, they adjusted their behavior accordingly when such a dominant individual was replaced with another one who had not witnessed the baiting procedure, thereby demonstrating their ability to keep track of precisely who has witnessed what. Similarly, ravens and scrub jays, for example, seem to possess cognitive representations of what they believe observing conspecifics to know. They accordingly adjust their own caching strategies, to minimize potential pilfering (see, e.g., Bugnyar \& Heinrich, 2005; Emery \& Clayton, 2001).

20. Someone who understands that beliefs may be false grasps the special relation between mental state and reality: mental states are not direct reflections of reality, but representations, which may or may not be accurate. Thus, understanding false beliefs is considered a "cornerstone of social competence" (Onishi \& Baillargeon, 2005, p. 255). It clearly represents the developmental change from a nonrepresentational to a representational ToM.

21. By "monolithic" we mean, with reference to Tomasello et al. (2003a), intrinsically indivisible.

22. Charles Darwin (1879/2004) stated in chapter 6 of The Descent of Man that "the mental faculties of man and the lower animals do not differ in kind, although immensely in degree." He concluded that "a difference in degree, however great, does not justify us in placing man in a distinct kingdom" (p. 173). He rejected the idea of a linear scala naturae, proceeding from "lower animals" to humans as the "pride of creation." Darwin clearly applied ideas of continuity and gradualism to animal abilities and characteristics 
and overthrew the dogma of separate creation. Yet although he denied fundamental differences in kind, Darwin's theory of evolution nevertheless allows the possibility that many gradual steps can eventually lead to profound differences, including with respect to mental capacities (for a good discussion of Darwin and his theories, see Engels, 2007, especially pp. 66-68, 74-76, 146-158, 166, and 197-204). However, according to the theory of evolution, species are ideally matched to their biological niches, and additional development would frequently constitute a biologically unjustified expenditure of energy. Describing animals as "higher" or "lower" in a normative way fails to adequately reflect this reality. Additionally, Darwin's theory allows the possibility of convergent evolution, resulting, for example, in complex mental faculties in animals, such as birds, to whom we are only distantly related.

23. This test is also known as the Location-Change Task. It was developed by Wimmer and Perner (1983) and modified by Baron-Cohen, Leslie, and Frith (1985), who named it the SallyAnne Test. Other falsebelief tests are the Deceptive-Box Test and the Appearance-Reality Test (see Call \& Tomasello, 1999, p. 381).

24. This refers to the false-belief test in its several versions.

\section{See http://childes.psy.cmu.edu}

26. For the different types of contrastives, see Bartsch \& Wellmann (1995), p. 32, and Shatz, Wellmann, and Silber (1983), p. 309.

\section{Growth and development.}

28. Throughout the history of philosophy and anthropology, the human being has always been characterized by the formula "the human is an animal plus X" (Wild, 2008, p. 26). According to this formula, humans have, for example, been characterized as the rational animal, the animal endowed with language and hands, or the animal who forms communities (Aristotle) and as the animal who has a soul (Descartes); has the ability to reason, including moral reasoning (Kant); has knowledge about death (Hölderlin); or has extraordinary adaptive abilities (Dostojewskij). Humans have been described as the animal who is not fixed (Nietzsche), who has an eccentric position (Plessner), or who has a world (Heidegger; see Wild, 2008, p. 26). Several books provide an overview or discussion of these and other classical characterizations that rely on purported cognitive, social, and psychological differences between humans and animals. Matthew Calarco's (2008) book Zoographies, for example, challenges the anthropocentrism of the Continental philosophical tradition and calls for the abolition of classical versions of the human-animal distinction. Schütt (1990) presents the main classical writings on animals' (supposedly absent) rationality, from Plato to Schopenhauer. Perler and Wild (2005) and Lurz (2009) concentrate on publications from the 20th and 21st centuries (e.g., addressing language, beliefs, representation, behavior, communication, mind-reading, and consciousness in animals). Kalof and Fitzgerald's The Animals Reader: The Essential Classic and Contemporary Writings (2007) presents a variety of perspectives on animals and humans, ranging from Aristotle to postmodern philosophers and from orangutans to cyborgs. It also contains contributions from a large range of cultural historians, ecological writers, and contemporary animal rights activists. An even more detailed approach to the human-animal relationship is given by the six volumes of the Cultural History of Animals, covering 4,500 years of human-animal interaction, from Antiquity to the Modern Age. Each volume also explores philosophical beliefs of the time (Kalof \& Resl, 2007).

29. Because of length constraints, we restricted this discussion mainly to the example of great apes. Furthermore, animal cognition research has clearly been primatocentric (Rogers \& Kaplan, 2004, p. 195), 
and ethical discussions often mirror this bias. We acknowledge, however, that many of the arguments presented here could similarly be applied to a range of other captive species.

\section{See http://wkprc.eva.mpg.de/english/files/enrichment.htm}

31. Additionally, not all problems associated with confining wild animals within zoos can be solved by environmental enrichment or other welfare improvements. Fundamental problems remain with zoos and the arguments used to legitimize them, some of which are explored in the following section. Another example is the purported conservation role of zoos, as promulgated by the World Association of Zoos and Aquariums and others. However, critics note that many zoos in late modernity are undergoing crucial changes, which are contrary to this conservation vision, and are very ethically problematic. It has been claimed that a "Disneyization" of zoos is observable, in which the major foci are entertainment and commercialization (see Beardsworth \& Bryman, 2001).

32. DeGrazia derives his rules from his first principle-the principle of nonmaleficence, which asserts that we should not cause "extensive unnecessary harm" to others. Rule 3 prohibits causing significant suffering for the sake of enjoyment. Hence, enjoyment is considered by DeGrazia to be a potential reason for causing harm that lacks sufficient necessity. This is highly relevant to the range of harms that zoos cause to their animals, given that a major purpose of zoos remains human entertainment.

33. However, DeGrazia's list was not exhaustive. Opportunities for foraging behavior, for example, should also be provided.

34. We believe that beings with sufficient characteristics should qualify for the status of personhood. We agree with Kant and others that such persons should posses certain inalienable rights, which are theoretically unable to be repudiated, surrendered, annulled, or transferred-that is, alienated, in any way. Nevertheless, we also recognize that scenarios existing in the real world (or even other theoretical worlds) may conflict with such theoretical ideals. For example, individuals may deliberately violate the rights of others, for personal gain. We do not consider such actions to be morally excusable. Individuals may also violate the rights of others as a result of unconscious reflexes-for example, in self-defense-or as a result of deliberate, rational choices, such as to achieve utilitarian objectives (when defending the equivalent rights of a greater number of others). In cases such as these, we consider such violations of otherwise inalienable rights to be morally excusable.

35. For evidence of emotional abilities in animals, see Bekoff (2007). It is possible that the ability to experience emotional states such as empathy may be a prerequisite for understanding and adhering to moral codes of behavior. For evidence of fairness in animals, see Bekoff (2007), pp. 85-109. For evidence of altruistic helping in chimpanzees, see Warneken and Tomasello (2006).

36. White (2007) uses the term "non-human persons," as does the Great Ape Project. DeGrazia (2006) prefers the term "borderline persons." Along with White and the Great Ape Project (Cavalieri \& Singer, 1994), others such as Wise (2000) and Diamond (2006) have questioned contemporary perceptions of the moral status of animals, or their legal status as human property (e.g., Francione, 1995).

37. Such experiments are mostly intended to benefit humans. However, large-scale systematic reviews have consistently demonstrated that their human benefits are usually minimal (Knight, 2007, 2008a, 2008c; Lindl, Völkel, \& Kolar, 2005), and a growing range of non-animal alternative research methodologies exist or are being developed (Knight, 2008b).

38. See Cavalieri and Singer (1994), especially pp. 8 and 12, as well as http://en.wikipedia .org/wiki/Great_Ape_Project 
39. There are different traditions underlying the concept of human dignity, including religious ones (asserting that human dignity derives from the creation of humans in the image of god); secular, philosophical ones (relying mainly on reasoning capacity or "natural law" to justify special moral status); and more empirical and historical ones (deducing the idea of human rights ex negativo from seeking to prevent recurrences of injustice); see Bayertz (1999). Similarly, traditions of human rights are diverse, ranging, for example, from liberal to naturalistic or ontological ones, and referring to ideas such as those deriving from transcendental philosophy or discourse theory (see Hilpert, 1998, pp. 674-675). However, despite traditional variety, modern secular foundations of human rights adhere closely to the philosophy of enlightenment and mainly to Kantian ideas (see, e.g., Hilpert, 1998, p. 675; similarly Bayertz, 1999, p. 824; Ganslandt, 1995, p. 847; Klenner, 1990, p. 367). Additionally, modern and postmodern philosophy linked the idea of human dignity and rights to the status of the person. Here again, influences came, for example, from Boethius, Rawls, and mainly Locke, but the most fundamental and eminent refinement goes back to Kant, who first conceptualized a direct connection between personhood and human rights within the Second Maxim (German: Selbstzweckformel) of his categorical imperative (see Sturma, 2002).

40. White refers to Diana Reiss (1990), who described dolphins as "an alien intelligence" (Reiss, 1990, p. 32).

\section{References}

Baron-Cohen, S., Leslie, A. M., \& Frith, U. (1985). Does the autistic child have a "theory of mind"? Cognition, 21, 37-46.

Bartels, A. (2005). Kognitive Ethologie: Repräsentationale Theorien des Verhaltens. In Strukturale Repräsentation (pp. 156-186). Paderborn, Germany: Mentis.

Bartsch, K., \& Wellmann, H. M. (1995). Children talk about the mind. Oxford, England: Oxford University Press.

Bayertz, K. (1999). Menschenwürde. In H. J. Sandkühler, D. Pätzold, A. Regenbogen, \& P. StekelerWeithofer (Eds.), Enzyklopädie Philosophie (Vol. 1, pp. 824-826). Hamburg, Germany: Meiner.

Beardsworth, A., \& Bryman, A. E. (2001). The wild animal in late modernity: The case of the disneyization of zoos. Tourist Studies, 1, 83-104.

Bekoff, M. (2007). The emotional lives of animals: A leading scientist explores animal joy, sorrow, and empathy-and why they matter. Novato, CA: New World Press.

Benz, J. (2004). Epistemische Ausdrücke in der Kindersprache. Eine linguistische Korpusuntersuchung zum Erstspracherwerb mit quantitativer und qualitativer Auswertung. Unpublished master's (state exam) thesis, University of Tübingen, Tübingen, Germany.

Bischof-Köhler, D. (2000). Kinder auf Zeitreise: Theory of Mind, Zeitverständnis und Handlungsorganisation. Bern, Switzerland: Huber.

Boesch, C., \& Boesch, H. (1983). Optimization of nut-cracking with natural hammers by wild chimpanzees. Behaviour, 83, 265-286.

Breuer, T., Ndoundou-Hockemba, M., \& Fishlock, V. (2005, November). First observation of tool use in wild gorillas. PloS Biology, 3(11), e380. 
Bugnyar, T., \& Heinrich, B. (2005). Ravens, Corvus corax, differentiate between knowledgeable and ignorant competitors. Proc Biol Sci, 272, 1641-1646.

Buttlemann, D., Carpenter, M., \& Tomasello, M. (2009). Eighteen-month-old infants show false belief understanding in an active helping paradigm. Cognition, 112, 337-342.

Calarco, M. (2008). Zoographies: The question of the animal from Heidegger to Derrida. New York, NY: Columbia University Press.

Call, J., \& Tomasello, M. (1999). A nonverbal false belief task: The performance of children and great apes. Child Development, 70(2), 381-395.

Call, J., \& Tomasello, M. (2008). Does the chimpanzee have a theory of mind? 30 years later. Trends in Cognitive Sciences, 12(5), 187-192.

Cavalieri, P., \& Singer, P. (Eds.). (1994). Menschenrechte für die Große Menschenaffen: Das Great Ape Projekt. München, Germany: Wilhelm Goldmann.

Conard, N. J. (2007). Cultural evolution in Africa and Eurasia during the middle and late pleistocene. In W. Henke \& I. Tattersall (Eds.), Handbook of paleoanthropology (pp. 2001-2037). New York, NY: Springer.

Darwin, C. (2004). The descent of man, and selection in relation to sex (J. Murray, Ed.). London, England: Penguin Books. (Original work published 1879)

Davidson, D. (1982). Rational animals. Dialectica, 36(4), 317-327.

DeGrazia, D. (1996). Taking animals seriously: Mental life and moral status. Cambridge, England: Cambridge University Press.

DeGrazia, D. (2006). On the question of personhood beyond Homo sapiens. In P. Singer (Ed.), In defense of animals. The second wave (pp. 40-53). Oxford, England: Blackwell.

Diamond, J. (2006). Der dritte Schimpanse: Evolution und Zukunft des Menschen. Frankfurt am Main, Germany: Fischer.

Emery, N. J., \& Clayton, N. S. (2001). Effects of experience and social context on prospective caching strategies by scrub jays. Nature, 414, 243-246.

Engels, E.-M. (2007). Charles Darwin. München, Germany: C. H. Beck. Fouts, R. (2000, July/August). My best friend is a chimp. Psychology Today, 223. Retrieved from http://www.psychologytoday.com/articles/200007/my-best-friend-is-chimp

Fragaszy, D. M., \& Perry, S. (Eds.). (2003). The biology of traditions: Models and evidence. Cambridge, England: Cambridge University Press.

Francione, G. L. (1995). Animals, property, and the law. Philadelphia, PA: Temple University Press.

Ganslandt, H. R. (1995). Menschenrechte. In J. Mittelstraß (Ed.), Enzyklopädie Philosophie und Wissenschaftstheorie (Vol. 2, pp. 846-847). Stuttgart, Germany: Metzler.

Gardner, R. A., \& Gardner, B. T. (1975). Evidence for sentence constituents in the early utterances of child and chimpanzee. Journal of Experimental Psychology-General, 104, 244-267. 
Gigon, O. (2002). Die philosophische Ethik der Griechen. In Aristoteles: Die Nikomachische Ethik. Translation, commentaries and introduction (pp. 53-75). München, Germany: dtv.

Goodall, J. (1964). Tool-using and aimed throwing in a community of free-living chimpanzees. Nature, 201, 1264-1266.

Gopnik, A., Slaughter, V., \& Meltzoff, A. N. (1994). Changing your views: How understanding visual perception can lead to a new theory of the mind. In C. Lewis \& P. Mitchell (Eds.), Children's early understanding of mind: Origins and development (pp. 157-181). Hillsdale, NY: Erlbaum.

Gould, J. L., \& Gould, C. G. (1999). The animal mind. New York, NY: Scientific American Library. Grant, R. (1996). Culture. In P. B. Clarke \& A. Linzey (Eds.), Dictionary of ethics, theology and society (pp. 206212). New York, NY: Routledge.

Griffin, D. R. (1976). The question of animal awareness: Evolutionary continuity of mental experience. New York, NY: Rockefeller University Press.

Hare, B., Call, J., Agnetta, B., \& Tomasello, M. (2000). Chimpanzees know what conspecifics do and do not see. Animal Behaviour, 59, 771-785.

Hare, B., Call, J., \& Tomasello, M. (2001). Do chimpanzees know what conspecifics know? Animal Behaviour, 61, 139-151.

Hauser, M. D. (2001). Wild minds: What animals really think. London, England: Penguin Books.

Hermann, L. M., Richards, D. G., \& Wolz, J. P. (1984). Comprehension of sentences by bottlenosed dolphins. Cognition, 16, 129-219.

Hernandez-Aguilar, R. A., Moore, J., \& Rayne Pickering, T. (2007). Savanna chimpanzees use tools to harvest the underground storage organs of plants. Proceedings of the National Academy of Science, 104(49), 19210-19213.

Hilpert, K. (1998). Menschenrechte. In W. Korff, L. Beck, \& P. Mikat (Eds.), Lexikon der Bioethik (Vol. 2, pp. 670-679). Gütersloh, Germany: Gütersloher Verlagshaus.

Hirata, S. (2006). Chimpanzee learning and transmission of tool use to fish for honey. In T. Matsuzawa, M. Tomanaga, \& M. Tanaka (Eds.), Cognitive development in chimpanzees (pp. 201-213). Tokyo, Japan: Springer.

Hoad, T. F. (Ed.). (1991). The concise Oxford dictionary of English etymology. Oxford, England: Clarendon Press.

Hoffmann, L. (2007). Der Mensch und seine Sprache-eine anthropologische Skizze. In A. Redder (Ed.), Diskurse und Texte. Festschrift für Konrad Ehlich zum 65 Geburtstag (pp. 21-37). Tübingen, Germany: Stauffenburg.

Horner, V., \& Whiten, A. (2005). Causal knowledge and imitation/emulation switching in chimpanzees (Pan troglodytes) and children. Animal Cognition, 8, 164-181.

Hülsken, C. (2001). Training in der Theory of Mind-Forschung. Die Rolle von Kohärenz und Feedback in der Entwicklung einer naiven Alltagspsychologie. Aachen, Germany: Shaker. 
Hunt, G. R., \& Gray, R. D. (2003). Diversification and cumulative evolution in New Caledonian crow tool manufacture. Proceedings of the Royal Society of London, 270(1517), 867-874.

Hutchins, M., Kleiman, D. G., Geist, V., \& McDade, M. C. (2003). Mammals and humans: Mammals in zoos. In M. Hutchins, D. G. Kleiman, V. Geist, \& M. C. McDade (Eds.), Grzimek's animal life encyclopedia: Vol. 12. Mammals I (2nd ed., pp. 203-212). Farmington Hills, MI: Gale Group.

Janik, V. M., Sayigh, L. S., \& Wells, R. S. (2006). Signature whistle shape conveys identity information to bottlenose dolphins. Proceedings of the National Academy of Sciences of the United States of America, 103(21), 8293-8297.

Jantschke, F. (1997). Zoo- und Zirkustiere. In H. H. Sambraus \& A. Steiger (Eds.), Das Buch vom Tierschutz (pp. 402-423). Stuttgart, Germany: Ferdinand Enke.

Kalof, L., \& Fitzgerald, A. J. (Eds.). (2007). The animals reader: The essential classic and contemporary writings. Oxford, England: Berg.

Kalof, L., \& Resl, B. (Eds.). (2007). A cultural history of animals (Vols. 1-6). Oxford, England: Berg.

Kaminski, J., Call, J., \& Tomasello, M. (2008). Chimpanzees know what others know, but not what they believe. Cognition, 109, 224-234.

Kant, I. (2008). Grundlegung zur Metaphysik der Sitten (T. Valentiner, Ed.). Stuttgart, Germany: Reclam. (Original work published 1785/1786)

Kasten, H. (2005). 4-6 Jahre: Entwicklungspsychologische Grundlagen. Weinheim, Germany: Beltz.

Kenward, B., Weir, A. A. S., Rutz, C., \& Kacelnik, A. (2005). Tool manufacture by naïve juvenile crows. Nature, 433, 121.

Kenward, B., Rutz, C., Weir, A. A. S., \& Kacelnik, A. (2006). Development of tool use in New Caledonian crows: Inherited action patterns and social influence. Animal Behaviour, 72, 1329-1343.

Klann-Delius, G. (1999). Sprachlernleistungen bei subhumanen Primaten. In Spracherwerb (pp. 81-85). Stuttgart, Germany: Metzler.

Klenner, H. (1990). Menschenrechte. In H. J. Sandkühler (Ed.), Europäische Enzyklopädie zu Philosophie und Wissenschaften (Vol. 3, pp. 366-372). Hamburg, Germany: Meiner.

Knight, A. (2007). The poor contribution of chimpanzee experiments to biomedical progress. Journal of Applied Animal Welfare Science, 10(4), 281-308.

Knight, A. (2008a). The beginning of the end for chimpanzee experiments? Philosophy, Ethics \& Humanities in Medicine, 3(16). Retrieved from http://www.peh-med.com/content/3/1/16

Knight, A. (2008b). Non-animal methodologies within biomedical research and toxicity testing. Alternatives to Animal Experimentation, 25(3), 213-231.

Knight, A. (2008c). Systematic reviews of animal experiments demonstrate poor contributions toward human healthcare. Reviews on Recent Clinical Trials, 3(2). Retrieved from http:// www.benthamdirect.org/pages/b_viewarticle.php?articleID=3148332 
Krachun, C., Carpenter, M., Call, J., \& Tomasello, M. (2009). A competitive nonverbal false belief task for children and apes. Developmental Science, 12(4), 521-535.

Krützen, M., Mann, J., Heithaus, M. R., Connor, R. C., Bejder, L., \& Sherwin, W. B. (2005). Cultural transmission of tool use in bottlenosed dolphins. Proceedings of the National Academy of Sciences of the United States of America, 102(25), 8939-8943.

Lindl, T., Völkel, M., \& Kolar, R. (2005). Tierversuche in der biomedizinischen Forschung. Eine Bestandsaufnahme der klinischen Relevanz von genehmigten Tierversuchsvorhaben: Nach 10 Jahren keine Umsetzung in der Humanmedizin nachweisbar. Alternatives to Animal Experimentation, 3, 143151.

Lonsdorf, E. V. (2006). What is the role of mothers in the acquisition of termite-fishing behaviors in wild chimpanzees (Pan troglodytes schweinfurthii)? Animal Cognition, 9, 36-46.

Lurz, R. W. (Ed.). (2009). The philosophy of animal minds. Cambridge, England: Cambridge University Press.

Matsuzawa, T., Biro, D., Humle, T., Inoue-Nakamura, N., Tonooka, R., \& Yamakoshi, G. (2001). Emergence of culture in wild chimpanzees: Education by master-apprenticeship. In T. Matsuzawa (Ed.), Primate origins of human cognition and behaviour (pp. 557-574). Tokyo, Japan: Springer.

McFarland, D. (2006). Oxford dictionary of animal behavior. Oxford, England: Oxford University Press.

McGrew, W. C., \& Tutin, C. E. G. (1978). Evidence for a social custom in wild chimpanzees? Man, 13, 234-251.

Newen, A., \& Bartels, A. (2007). Animal minds and the possession of concepts. Philosophical Psychology, 20(3), 283-308.

Onishi, K. H., \& Baillargeon, R. (2005). Do 15-month-old infants understand false beliefs? Science, 308, 255-258.

Ouattara, K., Lemasson, A., \& Zuberbühler, K. (2009). Campbell's monkeys concatenate vocalizations into context-specific call sequences. Proceedings of the National Academy of Sciences of the United States of America, 106(51), 22026-22031.

Pepperberg, I. M. (2002). The Alex studies: Cognitive and communicative abilities of Grey parrots. Cambridge, MA: Harvard University Press.

Pepperberg, I. M. (2008). Alex and me. New York, NY: Harper Collins.

Perler, D., \& Wild, M. (2005). Der Geist der Tiere. Philosophische Texte zu einer aktuellen Diskussion. Frankfurt am Main, Germany: Suhrkamp.

Povinelli, D. J., \& Vonk, J. (2003). Chimpanzee minds: Suspiciously human? Trends in Cognitive Sciences, 7(4), 157-160.

Premack, D., \& Woodruff, G. (1978). Does the chimpanzee have a theory of mind? The Behavioral and Brain Sciences, 4, 515-526.

Reiss, D. (1990). The dolphin: An alien intelligence. In B. Bova \& B. Preiss (Eds.), First contact: The search for extraterrestrial intelligence (pp. 31-40). New York, NY: New American Library. 
Rogers, L. J., \& Kaplan, G. (2004). All animals are not equal: The interface between scientific knowledge and legislation for animal rights. In C. R. Sunstein \& M. C. Nussbaum (Eds.), Animal rights: Current debates and new directions (pp. 175-202). Oxford, England: Oxford University Press.

Rogoff, B. (2003). The cultural nature of human development. Oxford, England: Oxford University Press.

Sanz, C., Call, J., \& Morgan, D. (2009). Design complexity in termite-fishing tools of chimpanzee (Pan troglodytes). Biology Letters, 5, 293-296.

Sanz, C., Morgan, D., \& Gulick, S. (2004). New insights into chimpanzees, tools and termites from the Congo Basin. The American Naturalist, 164, 567-581.

Sanz, C. M., Schöning, C., \& Morgan, D. B. (2009). Chimpanzees prey on army ants with specialized tool set. American Journal of Primatology, 71, 1-8.

Schütt, H. P. (Ed.). (1990). Die Vernunft der Tiere. Frankfurt am Main, Germany: Keip.

Seidenberg, M. S., \& Petitto, L. A. (1979). Signing behaviour in apes: A critical review. Cognition, 7, 177215.

Semaw, S. (2000). The world's oldest stone artefacts from Gona, Ethiopia: Their implications for understanding stone technology and patterns of human evolution between 2.6-1.5 million years ago. Journal of Archaeological Science, 27(12), 1197-1214.

Seyfarth, R. M., \& Cheney, D. L. (1993, February). Wie Affen sich verstehen. Spektrum der Wissenschaft, 2, 88-95.

Shatz, M., Wellmann, H. M., \& Silber, S. (1983). The acquisition of mental verbs: A systematic investigation of the first reference to mental state. Cognition, 14, 301-321.

Sommer, V. (2007). Darwinisch Denken. Horizonte der Evolutionsbiologie. Stuttgart, Germany: Hirzel.

Sturma, D. (2002). Person. In H. J. Sandkühler (Ed.), Enzyklopädie Philosophie [CD-ROM]. Hamburg, Germany: Meiner.

Taylor, A. H., Hunt, G. R., Holzhaider, J. C., \& Gray, R. D. (2007). Spontaneous metatool use by New Caledonian crows. Current Biology, 17, 1504-1507.

Tietz, S., \& Wild, M. (2006). Denken Tiere? Information Philosophie, 3, 14-26.

Tomasello, M., Call, J., \& Hare, B. (2003a). Chimpanzees understand psychological states-The question is which ones and to what extent. Trends in Cognitive Sciences, 7(4), 153-156.

Tomasello, M., Call, J., \& Hare, B. (2003b). Chimpanzees versus humans: It's not that simple. Trends in Cognitive Sciences, 7(4), 239-240.

Van Schaik, C. P., Ancrenaz, M., Borgen, G., Galdikas, B., Knott, C. D., Singleton, I., et al. (2003). Orangutan cultures and the evolution of material culture. Science, 299(102), 102-105.

Van Schaik, C. P., van Noordwijk, M. A., \& Wich, S. A. (2006). Innovation in wild Bornean orangutans (Pongo pygmaeus wurmbii). Behaviour, 143, 839-876. 
Warneken, F., \& Tomasello, M. (2006). Altruistic helping in human infants and young chimpanzees. Science, 311(5765), 1301-1303.

Weir, A. A. S., Chappell, J., \& Kacelnik, A. (2002). Shaping of tools in New Caledonian Crows. Science, 297, 981.

White, T. (2007). In defense of dolphins: The new moral frontier. Malden, MA: Blackwell.

Whiten, A., Goodall, J., McGrew, W. C., Nishida, T., Reynolds, V., Sugiyama, Y., et al. (1999). Cultures in chimpanzees. Nature, 399, 682-685.

Whiten, A. (2005). The second inheritance system of chimpanzees and humans. Nature, 437, 52-55.

Whiten, A., Horner, V., \& de Waal, F. B. M. (2005). Conformity to cultural norms of tool use in chimpanzees. Nature, 437, 737-740.

Wild, M. (2008). Tierphilosophie zur Einführung. Hamburg, Germany: Junius.

Wimmer, H., \& Perner, J. (1983). Beliefs about beliefs: Representation and constraining function of wrong beliefs in young children's understanding of deception. Cognition, 13, 103-128.

Wise, S. M. (2000). Rattling the cage: Toward legal rights for animals. Cambridge, MA: Perseus Books.

Workman, L., \& Reader, W. (2004). Evolutionary psychology: An introduction. Cambridge, England: Cambridge University Press. 